\title{
Bilateral tunnel vision as the first presenting sign of levamisole-induced vasculitis
}

\author{
Maria Sofia Cotelli*, Gina Alessandra Gregorini², Doriana Polonioli', Marinella Turla \\ 'Department of Neurology, Neurological Unit, ASST Valcamonica-Esine, Brescia, Italy, ²Department of Nephrology, ASST \\ Spedali Civili, Brescia, Italy
}

\begin{abstract}
Levamisole-contaminated cocaine is an increasingly reported cause of a syndrome characterized by vasculitic skin lesions and immunologic abnormalities. With approximately $70 \%$ of cocaine in the United States now contaminated with levamisole, the incidence of this syndrome is likely to increase. We report the case of a 42 years-old Caucasian woman who presented with fronto-temporal pulsating headache and progressive bilateral loss of vision.
\end{abstract}

Key words: levamisole; vasculitis; cocaine

\section{INTRODUCTION}

Levamisole-contaminated cocaine is an increasingly reported cause of a syndrome characterized by vasculitic skin lesions and immunologic abnormalities. With approximately $70 \%$ of cocaine in the United States now contaminated with levamisole, the incidence of this syndrome is likely to increase.

\section{CASE REPORT}

We report the case of a 42-year-old Caucasian woman who underwent our observation due to frontotemporal pulsating headache and progressive bilateral loss of vision with the inability to see in dim light or at night (nyctalopia), lasting for 1 month.

\footnotetext{
*Corresponding author: Maria Sofia Cotelli, Neurological Unit ASST Valcamonica, Via Manzoni 142, Esine, Brescia, Italy. E-mail: cotellim@gmail.com
}

Submitted: 12 January 2018/Accepted: 30 March 2018
Medical and social history was positive for chronic cocaine abuse, high alcohol intake, previous right retinal hemorrhage, and hospitalization for pericarditis and paroxysmal supraventricular tachycardia. Neurological examination resulted in normal findings except for bilateral tunnel vision (Figure 1). The patient underwent brain computed tomography (CT), magnetic resonance imaging (MRI), and magnetic resonance angiography (angio-MRI) which were within normal limits (Figure 2). In addition, maxillofacial CT was performed showing chronic sinusitis and chronic parodontopathy, resulting from previous nasal septum perforation. Visual field testing showed bilateral centrocecal scotomas. Nasal septum biopsy showed necrosis and chronic mucositis. Optical coherence tomography displayed bilateral thinning of temporal fibers. Blood examinations showed high titer of antineutrophil cytoplasmic antibodies (ANCA): pANCA/MPO, 85.7 (normal values negative); anti-nuclear antibodies 1:80 (normal values negative); slight increase of end-systolic 


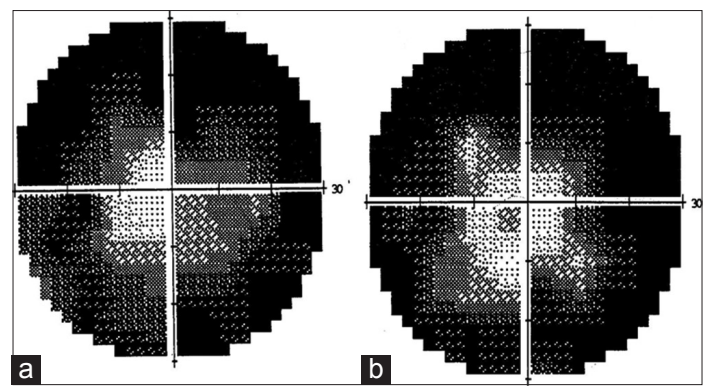

FIGURE 1. Bilateral tunnel vision in levamisole-induced vasculitis. (a) Visual field left eye, (b) visual field right eye.
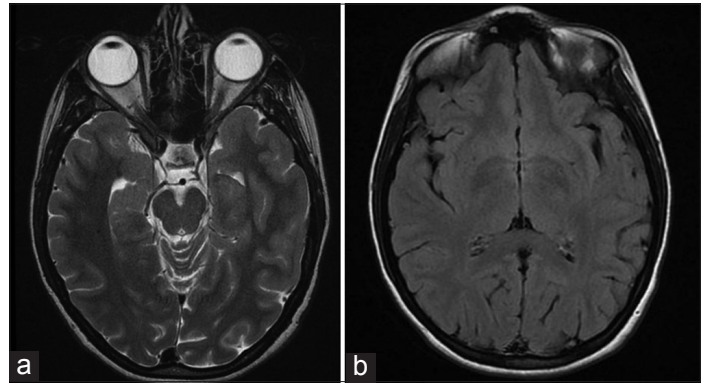

FIGURE 2. Brain magnetic resonance imaging (MRI) T2 (a) and MRI fluid attenuation inversion recovery (b) findings in levamisole-induced vasculitis.

volume of $50 \mathrm{~mm}$ (normal range $1-32 \mathrm{~mm}$ ), and RCP of 70.1 (normal value $<5$ ). Both complete blood count and renal function parameters were normal. Urine toxicological tests were positive for cocaine. Levamisole was not tested.

Prednisone $1 \mathrm{mg} / \mathrm{kg} /$ daily was initiated. After 1 month of therapy, there was an improvement in the general condition an improvement of general condition with consequent reduction of the dose. The patient was devoid of cocaine during the therapy.

\section{DISCUSSION}

Levamisole is a synthetic imidazothiazole derivative which was originally marketed as an anthelmintic agent but was also found to have major immunomodulatory properties (1). It induced interferon synthesis and synergized the effect of steroids and other immunosuppressants (2). It was used in cancer therapy such as colon and breast cancer or to treat various immunological renal diseases, such as pediatric nephrotic syndrome. Further, it was used to treat a number of skin diseases, including Behçet's disease and rheumatoid arthritis. However, the drug was withdrawn from the market in the United States in 2000 and in Canada in 2003 because of serious side effects. It is still available as a veterinarian deworming drug in the United States and South America $(2,3)$.

The mechanism of the action of levamisole as an antiparasitic agent appears to be tied to its agonistic activity toward the L-subtype nicotinic acetylcholine receptors in nematode muscles. This agonistic action reduces the capacity of the males to control their reproductive muscles and limits their ability to copulate (4).

The effects of levamisole on the immune system are complex. The drug appears to restore depressed immune function rather than to stimulate the response to above normal levels (4). Levamisole can stimulate the formation of antibodies to various antigens, enhance T-cell responses by stimulating T-cell activation and proliferation, potentiate monocyte and macrophage functions including phagocytosis and chemotaxis, and increase neutrophil mobility, adherence, and chemotaxis (5).

Levamisole is readily absorbed from the gastrointestinal tract and metabolized in the liver. It achieves peak plasma concentration in 1.5-2 h (6). Its plasma elimination half-life is $3-4 \mathrm{~h}$, which is fairly short and may often be the reason for negative toxicological tests that detect levamisole (7). Levamisole rapidly metabolizes to aminorex and related metabolites, which have a half-life of about $16 \mathrm{~h}(6,8)$. Levamisole excretion is primarily through the kidneys, with about $70 \%$ being excreted over 3 days (5). Only about 5\% is excreted as unchanged levamisole (7).

Aminorex is an amphetamine-like agent that was detected in racehorses after levamisole administration (8). Aminorex was marketed as an appetite suppressant in the mid-1960s mainly in Switzerland, Austria, and Germany; it was found to cause pronounced vasoconstriction in the pulmonary vasculature and was withdrawn in 1972 due to several cases of fatal and life-threatening pulmonary hypertension (8).

Levamisole has also been recognized as an adulterant in illicit cocaine since 2003. A 2009 national 
TABLE 1. Levamisole common effects on the human body

\begin{tabular}{|c|c|}
\hline Levamisole manifestations & Literature review \\
\hline \multicolumn{2}{|l|}{ Dermatological involvement } \\
\hline Erythema elevatum diutinum-Like vasculitis & Ewan et al. 2018 \\
\hline Vanishing vasculitis & Ghias et al. 2018 \\
\hline Generalized fatal vasculitis & Hammond et al. 2017 \\
\hline Pyoderma gangrenosum & Seghal R et al. 2017 Jeong et al. 2016 \\
\hline Retiform purpura & Nelson N et al. 2016 Walsh NM et al. 2010 Han et al. 2011 \\
\hline Eyelid necrosis and secondary cicatrical ectropion & Ramesh et al. 2017 \\
\hline $\begin{array}{l}\text { Delayed recurrent vasculitis with varying vasculitic antibodies over } \\
\text { the years. }\end{array}$ & Yogarajah 2015 \\
\hline Facial necrosis & Formeister et al. 2015 \\
\hline \multicolumn{2}{|l|}{ Intestinal involvement } \\
\hline Ileal intussusception & van der Veer et al. 2017 \\
\hline Bowel ischemia & Khan et al. 2018 \\
\hline \multicolumn{2}{|l|}{ Osteoscheletrical involvement } \\
\hline Arthralgia and myalgia & van der Veer et al. 2017 \\
\hline Extremity bone necrosis with amputation & Ching 2012 \\
\hline \multicolumn{2}{|l|}{ Otolaryngologic manifestation } \\
\hline Otolaryngologic manifestations & Alemi et al. 2016 \\
\hline \multicolumn{2}{|l|}{ Cardiopulmonary involvement } \\
\hline Acute coronary syndrome & Michaud et al. 2014 \\
\hline Isolated pulmonary vasculitis & Karch 2016 \\
\hline \multicolumn{2}{|l|}{ Central nervous system involvement } \\
\hline Multifocal inflammatory leukoencephalopathy & Vitt JR et al. 2017 Vosoughi and Schmidt \\
\hline Recurrent leukoencephalopathy & González-Duarte and Williams \\
\hline \multicolumn{2}{|l|}{ Peripheral nervous system involvement } \\
\hline Myopathy & Tsai et al. 2013 \\
\hline \multicolumn{2}{|l|}{ Renal involvement } \\
\hline Nephrotic sindrome & Alvarez Diaz et al. 2013 \\
\hline Crescentic glomerulonephritis & Chawdhary K et al. 2015 Carrara et al. 2016 \\
\hline Membranous nephropathy & Moinuddin et al. 2016 \\
\hline Spontaneous renal artery bleed & Machua et al. 2016 \\
\hline \multicolumn{2}{|l|}{ Pancreatic involvment } \\
\hline Acute pancreatitis & Ogunbameru et al. 2015 \\
\hline \multicolumn{2}{|l|}{ Atypical generalized pattern } \\
\hline Pseudovasculitis & Fan et al. 2017 \\
\hline
\end{tabular}

survey found that approximately $70 \%$ of cocaine in the USA is contaminated with levamisole (9). It is added to cocaine because it potentiates its stimulant effects by inhibiting both monoamine oxidase and catechol-O-methyltransferase activity, thereby prolonging the action of catecholamines in the neuronal synapse and increasing the reuptake inhibition effect of cocaine (4).

The concentration of levamisole in cocaine has steadily increased since it was first detected. The concentration was $<1 \%$ in 2001, and in 2009, levamisole comprised approximately $10 \%$ of each cocaine sample. In an analysis of cocaine users in Seattle, Washington, approximately $80 \%$ of users who tested positive for cocaine also tested positive for levamisole (10). Levamisole is also used to adulterate other illicit substances; seized heroin supplies in 2008 and 2009 were found to contain trace amounts of levamisole (10).

Furthermore, aminorex was detected in human urine samples in a multitude of cocaine abusers. It seems to 
TABLE 2. Hematological and laboratory findings in levamisole vasculitis

\begin{tabular}{lll}
\hline Haematological features & Frequency of presentation (\%) & Literature review \\
\hline Leukopenia & $28 \%$ of patients & Cascio ML et al. 2018 \\
& & Dezman Z et al. 2016 \\
Agranulocytosis/neutropenia & & Cherlopalle et al. 0016 \\
& & Khan MS et al. 2018 \\
& & Kassim T et al. 2018 \\
Anemia & $73 \%$ of patients & Srivastava R et al. 2017 \\
& & García MR Pérez et al. 2013 \\
Thrombocytopenia & $10 \%$ of patients & Cascio et al. 2018 \\
& & Cascio ML et al. 2018
\end{tabular}

\section{Laboratory findings}

$$
\text { CRP }
$$

ANA

Anti-DNA

ANCA

MPO

PR3

LAC

Anti cardiolipin

Anti-beta 2 GPI

C3

C4

Cryoglobulin
Elevated in $82.4 \%$ of patients

Positive in $57 \%$ of patients raging from 140 to 11280 , mostly homogeneous pattern

Positive in $23 \%$ of patients s raging from 110 to 1160

Positive in $93.8 \%$ of patients

Positive in $85 \%$ of patients

Positive in $32.2 \%$ of patients

Positive in $15.3 \%$ of patients

Positive in $42.3 \%$ of patients

Positive in $73 \%$ of patients

Positive in $24 \%$ (lgM), $14 \%$ ( $(\lg G)$ of patients

Both decreased in $16.1 \%$ of patients

Detected in about $19 \%$ of patients
Dartevel 2018

Cascio et al. 2018

Cascio ML et al. 2018

Cascio ML et al. 2018

Dartevel A et al. 2018

Dartevel A et al. 2018

Dartevel et al. 2018

Dartevel A et al. 2018

Cascio ML et al. 2018

Cascio et al. 2018

Dartevel et al. 2018

Dartevel et al. 2018

CRP: C-reactive protein), ESR: Erythrocyte sedimentation rate, ANA: Anti-nuclear Ab annti, DNA: Anti-deoxyribonucleic acid (anti-DNA), ANCA: Anti-neutrophil cytoplasmic antibodies, anti MPO: Anti-myeloperoxydase, PR3: Anti-proteinase 3, LAC: Lupus anticoagulant, Anti beta 2 GPI: Anti-ß2 glycoprotein 1, IgM: Immunoglobulin M, IgG0: Immunoglobulin G

exert strong effects on all three neurotransmitter monoamine transporters such as serotonin, norepinephrine, and dopamine in a manner similar to amphetamine (8). Levamisole-induced vasculitis (LIV) was first described in the 1970s (11). LIV is a cutaneous vasculitis that has been reported with smoked crack cocaine and inhaled cocaine powder. It has a greater frequency in women (male-to-female ratio 1:3), with a mean age of presentation of 44 years $(1,11)$. It is characterized by skin involvement, especially necrotic purpura located in the ears, leukoneutropenia, ANCAs, and/or anti-phospholipid Abs and good prognosis on levamisole cease. Although other compounds can be added to cocaine, vasculitis has been associated with long-term use of cocaine mixed with stimulants such as levamisole (12). Patients with LIV develop tender purpuric lesions 1-3 days after exposure (12). These lesions first develop as symmetric erythema, evolve into retiform purpura and bullae, and finally undergo necrosis and eschar formation (12). Most commonly, lesions develop over the ear, malar eminences, and tip of the nose. Diagnosis of LIV is on its clinical presentation and histopathological findings of leukocytoclastic vasculitis of small vessels containing fibrinous necrosis of the vessel wall, erythrocyte extravasation, and multiple fibrin thrombi within small vessels in the superficial and deep dermis (12).

Other recognized manifestations among cocaine abusers are pulmonary-renal syndrome (13), multifocal recurrent leukoencephalopathy with diffuse white matter involvement with sparing of the $U$ fibers, without brain stem or cerebellar involvement $(14,15)$, pyoderma gangrenosum (16), intravascular thrombosis, 
and less commonly crescentic nephritis, retiform purpura, and pauci-immune glomerulonephritis $(17,18)$. Common side effects are shown in Table 1, while common laboratory values are presented in Table 2 .

Bilateral tunnel vision has been described in various ocular diseases, such as retinitis pigmentosa (19), choroideremia (20), and glaucoma (21), but has never been described before as a presenting sign for levamisole vasculitis.

\section{CONCLUSION}

We described a case of levamisole-adulterated cocaine vasculitis with atypical symptoms of presentation, such as headache and bilateral tunnel vision, both improved after discontinuing cocaine abuse and starting treatment with prednisone. We think that expand literature for this entity helps specialists to considerate levamisole adulteration as a possible differential diagnosis when evaluating ocular signs in cocaine abuser patient. We think that bilateral tunnel vision can be considered as a manifestation of small vessel vasculitis with bilateral temporal fibers thinning, while headache can be considered a side effect of both chronic cocaine and levamisole abuse.

\section{REFERENCES}

1. Strazzula L, Brown KK, Brieva JC, Camp BJ, Frankel HC, Kissin E. Levamisole toxicity mimicking autoimmune disease. J Am Acad Dermatol 2013;69(6):954-9.

https://doi.org/10.1016/j.jaad.2013.07.037.

2. Abdul-Karim R, Ryan, C, Rangel C, Emmett M. Levamisole induced vasculitis Proc. Bayl Univ Med Cent 2013;26(2):163-5.

https://doi.org/10.1080/08998280.2013.11928946.

3. Berman M, Paran D, Elkayam O. Cocaine-induced vasculitis rambam Maimonides. Med J 2016;7(4):e0036.

4. Goldstein G. Mode of action of levamisole. JRheumatol Suppl 1978;4:143-8.

5. Carrara C, Emili S, Lin M Alpers CE. Necrotizing and crescentic glomerulonephritis with membranous nephropathy in a patient exposed to levamisole-adulterated cocaine. Clin Kidney J 2016;9(2):234-8.

https://doi.org/10.1093/ckj/sfv141.

6. Chang A, Osterloh J, Thomas J. Levamisole: A dangerous new cocaine adulterant. Clin Pharm Ther 2010;88:408.

https://doi.org/10.1038/clpt.2010.156.

7. Trehy ML, Brown DL, Woodruff JT, Westenberger BJ, Nychis WG,
Reuter N. Determination of levamisole in urine by gas chromatographymass spectrometry. J Anal Toxicol 2011;35(8):545-50.

https://doi.org/10.1093/anatox/35.8.545.

8. Hofmaier T, Luf A, Seddik A, Stockner T, Holy M, Freissmuth M. Aminorex, a metabolite of the cocaine adulterant levamisole, exerts amphetamine like actions at monoamine transporters. Neurochem Int 2014;73(2):32-41.

https://doi.org/10.1016/j.neuint.2013.11.010.

9. Casale JF, Corbeil EM, Patrick AH. Identification of levamisole impurities found in illicit cocaine exhibits. Microgram J 2008;6(3-4):82-9.

10. Lee KC, Ladizinski B, Federman DG. Complications associated with use of levamisole-contaminated cocaine: An emerging public health mayo. Clin Proc 2012;87(6):581-6.

https://doi.org/10.1016/j.mayocp.2012.03.010.

11. Roberts JA, Chévez-Barrios P. Levamisole-induced vasculitis: A characteristic cutaneous vasculitis associated with levamisole-adulterated cocaine. Arch Pathol Lab Med 2015;139(8):1058-61.

https://doi.org/10.5858/arpa.2014-0107-RS.

12. Sayadi L, Laub D. Levamisole-Induced Vasculitis. Eplasty 2018;18:ic5.

13. Restrepo-Escobar M, Sylva D, Gamboa JG, Echeverri A, Márquez J, Pinto LF. Pulmonary-renal syndrome secondary to cocaine-levamisole-induced vasculitis: A case report. Reumatol Clin 2018;2018: pii: S1699-258X.

14. González-Duarte A, Williams R. Cocaine-induced recurrent leukoencephalopathy. Neuroradiol J 2013;26(9):511-3.

https://doi.org/10.1177/197140091302600503.

15. Vosoughi R, Schmidt BJ. Multifocal leukoencephalopathy in cocaine users: A report of two cases and review of the literature. BMC Neurol 2015;15:208. https://doi.org/10.1186/s12883-015-0467-1.

16. Jeong HS, Layher H, Cao L, Vandergriff T, Dominguez AR. Pyoderma gangrenosum (PG) associated with levamisole-adulterated cocaine: Clinical, serologic, and histopathologic findings in a cohort of patients. J Am Acad Dermatol 2016;74(5):892-8.

https://doi.org/10.1016/j.jaad.2015.11.040.

17. Carlson AQ, Tuot DS, Jen KY, Butcher B, Graf J, Sam R, et al. Pauci-immune glomerulonephritis in individuals with disease associated with levamisole-adulterated cocaine: A series of 4 cases. Medicine 2014;93(17):290-7. https://doi.org/10.1097/MD.0000000000000090.

18. Veronese FV, Dode RS, Friderichs M Thomé GG, da Silva DR, Schaefer PG. Cocaine/levamisole-induced systemic vasculitis with retiform purpura and pauci-immune glomerulonephritis. Braz J Med Biol Res 2016;49(5):e5244.

https://doi.org/10.1590/1414-431X20165244.

19. Audere M, Rutka K, Šepetiene S, Lāce B. Presentation of complex homozygous allele in ABCA4 gene in a patient with retinitis pigmentosa. Case Rep Ophthalmol Med 2015;2015:452068.

20. Woods RL, Giorgi RG, Berson EL, Peli E. Extended wearing trial of trifield lens device for "tunnel vision". Ophthalmic Physiol Opt 2010;30(3):240-52. https://doi.org/10.1111/j.1475-1313.2010.00718.x.

21. Hu CX, Zangalli C, Hsieh M, Gupta L, Williams AL, Richman J, et al. What do patients with glaucoma see? Visual symptoms reported by patients with glaucoma. Am J Med Sci 2014;348:403-9.

https://doi.org/10.1097/MAJ.0000000000000319. 